\title{
Giant Mucocele of Maxillary Sinus, Scarce Occurrence: Case Report
}

\author{
Dr. Madhumita Srivastava ${ }^{1^{*}} \mid$ Dr. Sanjoy Chowdhury ${ }^{2} \mid$ Dr. Gaurav Vishal ${ }^{3}$
}

\begin{abstract}
${ }^{1}$ MDS (Oral \& Maxillofacial surgeon), MFDS, Sr. Consultant, SAIL. Bokaro General Hospital, 3C/223, Bokaro Steel City, Jharkhand, 827003, India

${ }^{2} \mathrm{MS}, \mathrm{DO}, \mathrm{DNB}, \mathrm{DSc}$ (Hon), Director (Medical and Health Services), Head Eye Dept. SAIL

${ }^{3} \mathrm{MD}$, Molecular Biology (I/C), SAIL
\end{abstract}

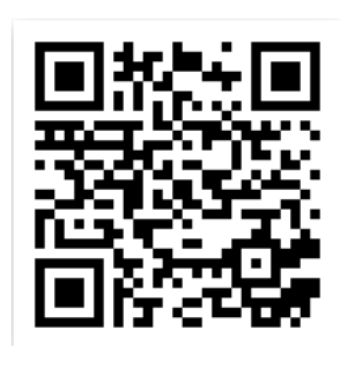

\begin{abstract}
Mucoceles are common pathology occurring still about paranasal sinuses it is less common and rare for maxillary sinus. Scare to scare is giant mucoceles of the maxillary sinus causing bone destruction in patients with no history of sinonasal surgery. To diagnose sinus pathology one must be well versed with the type of tissue that is present in the normal antrum, as a diseased or pathologic tissue is nothing but a modification of the normal. Here we present one such case of mucocele in the maxillary sinus which reported to us in a quite pronounced state. The mucocele had eroded the surrounding walls of the sinus, so it was essential and challenging to differentiate from malignancy. The case was thoroughly examined, investigated and lastly diagnosed as mucocele and treated successfully.

Keywords: Maxillary sinus, dental, sinogenic, radiographs, CT scan, Caldwell Luc

Copyright : (C) 2022 The Authors. Published by Medical Editor and Educational Research Publishers Ltd. This is an open access article under the CC BY-NC-ND license

(https://creativecommons.org/licenses/by-nc-nd/4.0/).
\end{abstract}

\section{1 | INTRODUCTION}

$\mathrm{K}$ nowledge about adjoining is imperative to have harmonious existence- That's about antrum pathology. An important step in the examination and management of antrum disease is an accurate diagnosis. To reach this goal one must be well versed with the type of tissue that is present in the normal antrum, as a diseased or pathologic tissue is nothing but a modification of the normal. Mucoceles are one of such pathology which is common for frontal-ethmoid sinuses $(89 \%)$ but very scarcely seen in the maxillary antrum (2.7$10 \%$ ). (1,2) Paranasal mucoceles commonly occur due to chronic sinus inflammation, trauma, previous

Supplementary information The online version of this article (https://doi.org/10.52845/JMRHS/20225-2-2) contains supplementary material, which is available to authorized users.

Corresponding Author: Dr. Madhumita Srivastava MDS (Oral \& Maxillofacial surgeon), MFDS, Sr. Consultant, SAIL. Bokaro General Hospital, 3C/223, Bokaro Steel City, Jharkhand, 827003, India 
surgery, and allergic disease but also one-third of the cases of it are idiopathic in origin. ${ }^{(3)}$ Scare to scare is giant mucoceles of the maxillary sinus causing bone destruction in patients with no history of sinonasal surgery and when mucoceles erode the surrounding walls of the sinus it must therefore be differentiated from malignancies. ${ }^{(4)}$ Here we present one such case of giant mucoceles of the maxillary sinus in a 58 years old female who reported our maxillofacial unit.

\section{CASE REPORT}

58 years old female reported, to our OPD with a gross swelling on her left side of the face for six months. The patient was ok six months back when she noted small swelling on her face which was painless. A Few days later she noticed that she is having difficulty in chewing also. Facial swelling gradually increased in size to the present size in a few months. There was a history of nasal obstruction. In between, she consulted local practitioners but with no relief. On examination a gross swelling on the left maxillary region was found, which was causing a bulge over the left cheek region. [Figure 1] Extra orally swelling extended superiorly to the infraorbital region, inferiorly up to the corner of the mouth, medially to the left lateral nasal wall, and laterally just anterior to the zygomatic arch. [Figure 2] It was a painless hard to touch swelling.

\section{Extra oral clinical presentation}

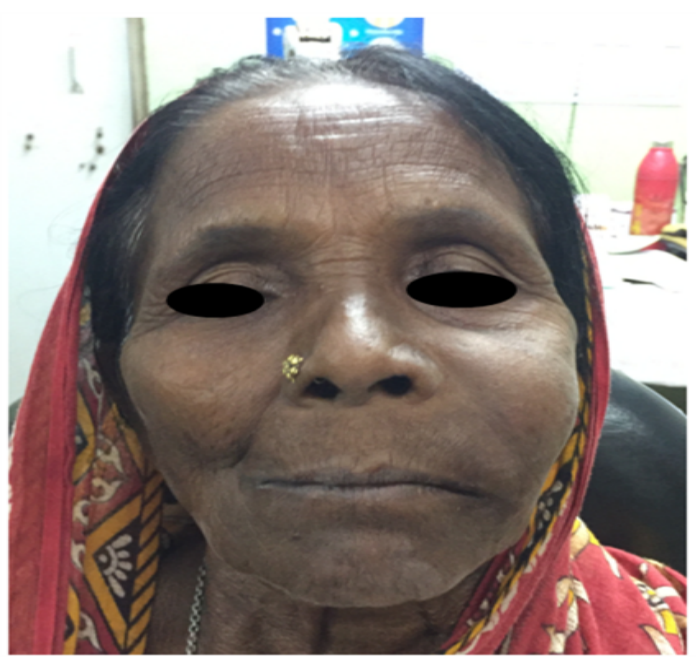

\section{FIGURE 1:}

Gross swelling over the left middle third of face

Extension of swelling: superiorly to the infraorbital region, inferiorly up to the corner of the mouth,

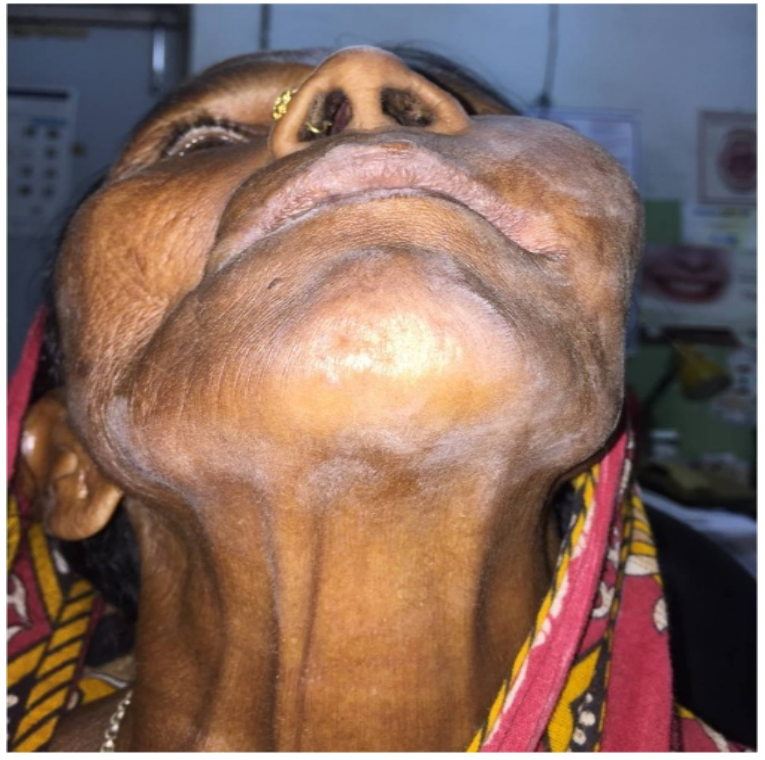

FIGURE 2:

medially to the left lateral nasal wall, and laterally just anterior to the zygomatic arch.

On physical examination, elastic there were no gaze palsies or visual acuity deficits. Gross swelling was also present intraorally measuring $3 * 4 \mathrm{~cm}$ in diameter causing obstruction of buccal vestibule and palatal displacement of maxillary posterior teeth, i.e. 25 and 26 [Figure 3] obstructing occlusion [Figure 4]. Intraorally swelling was firm in consistency except in the region of the buccal vestibule concerning 24 and 25 and displaced premolars ( $24 \& 25)$ medially. Vestibular deformation was seen from 22 to 27 regions. Just buccal to 24 there was the indentation of 34, which confirms that the patient was having difficulty in chewing. Fine needle aspiration (FNA) was done buccal to 24 and cytology showed low cellularity with focal collections of acute and chronic inflammatory cells, cystic macrophages. There was no evidence of neoplastic pathology. A Contrastenhanced computed tomography (CECT), paranasal sinus (PNS) was advised which demonstrated large expansile homogenous mass with scalloping and resorption of posteroinferior, medial, and superolateral walls of sinus [Figure 5]. The lesion was slightly pushing the lateral wall of the nasal cavity medially, occluding it [Figure 6].

\section{Intra oral clinical presentation}




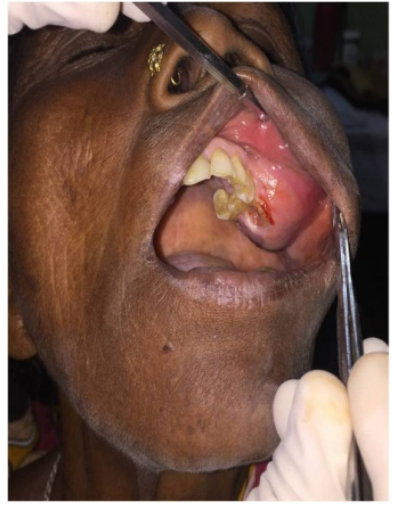

\section{FIGURE 3:}

Intra oral swelling causing obstruction of buccal vestibule and palatal displacement of maxillary posterior teeth

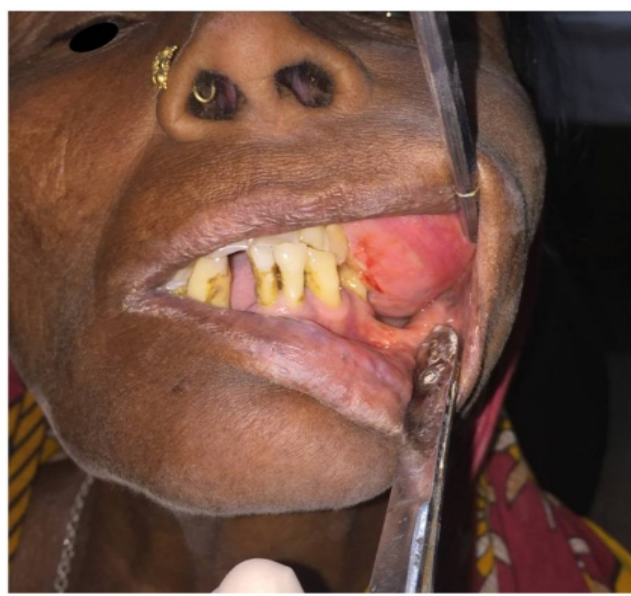

FIGURE 4:

Intra oral swelling causing occlusal obstruction Imaging

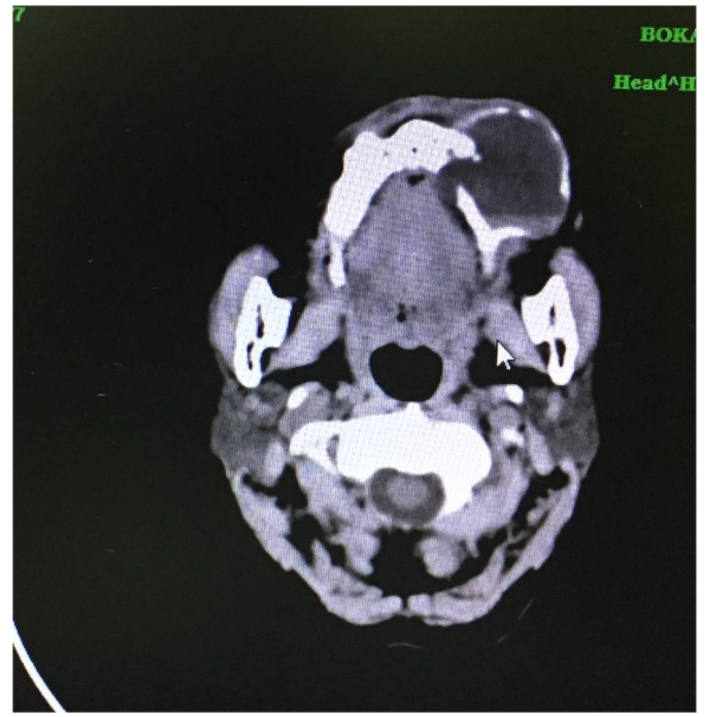

FIGURE 5:
CT Scan on axial section showing large expansile homogenous mass with scalloping and resorption of posteroinferior, medial, and superolateral walls of sinus

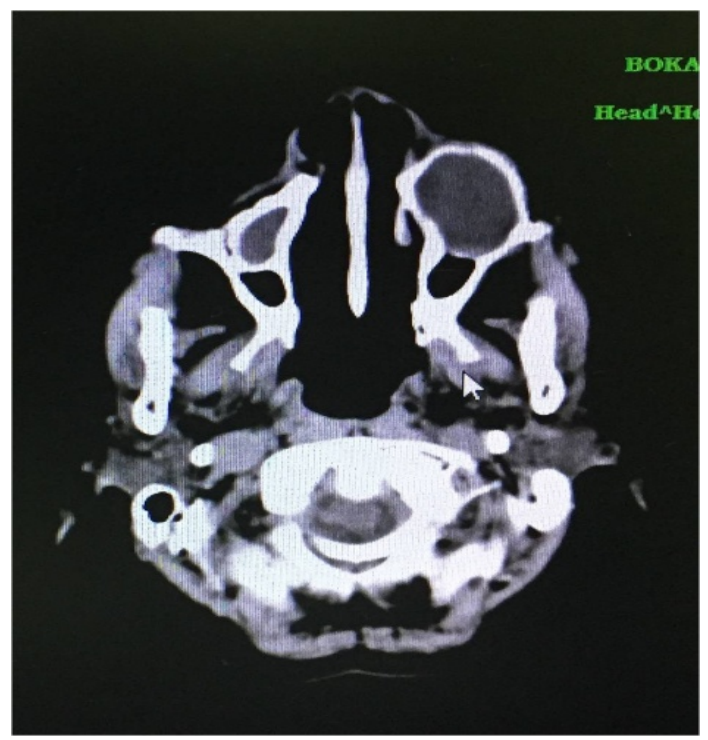

FIGURE 6:

Lesion slightly pushing the lateral wall of the nasal cavity medially and occluding it

Based on clinical examination, FNAC, and CECT findings provisional diagnosis of mucoceles was made. Considering the above diagnosis enucleation of mucoceles via Caldwell Luc was planned and executed. Intraoperatively $27 \mathrm{ml}$ of brownish clear fluid was drained out, the cystic lining was removed and meatal antrostomy was performed. Her 24 and 25 teeth were also extracted and the cystic lining was sent for histopathological evaluation. The histopathological report was consistent with the diagnosis of mucocele. Operative and postoperative periods were uneventful. The patient was followed up for regular 5 months with no recurrence of the same.

\section{2 | DISCUSSION}

Mucocele is defined as an abnormally dilated cavity in the body due to the accumulation of mucus. ${ }^{(5)} \mathrm{I}_{\mathrm{t}}$ is often described as a mucous retention cyst or cyst with true epithelial linings. In paranasal sinuses, this cyst is lined with respiratory epithelium enclosing 
mucoid secretions and epithelial debris with pseudo stratified columnar epithelium lining. (6)

Pathogenesis trailing progression of mucocele is hindered sinus secretions, which, if not gets outbreak, starts bolstering within the sinus and steadily decimate the bony wall due to pressure fallout. This bony massacre is a decisive element to extricate this pathology from chronic sinusitis, retention cysts, and extensive polyposis. Also these pressure effects engendered due to inflation are the rationale for trivial symptoms ensuing in mucocele. Symptoms may be as follows: 1) Facial swelling amidst infra-orbital anesthesia. 2) Medial extension en route nasal cavity pushing the inferior turbinate precipitating nasal obstruction, 3) Inferior expansion into the palatal and alveolar region leads to palatal swelling along with looseness of teeth and 4) Extension towards orbit, causes displacement of the eye, proptosis, ptosis, double vision, and epiphora. ${ }^{(7,8)}$

Four mechanisms can explain the reason for the occurrence of mucocele in the sinus. Firstly, it may arise from epithelial inclusion within the connective tissue stroma of the sinus lining. This inclusion can become cystic lately and start expanding, causing bony destruction due to pressure. The Second process postulates extravasations of mucus into the connective tissue stroma through a ruptured mucous gland. As this ruptured gland continues to produce mucus, it reflects the sinus lining backward gradually. This process leads to the formation of a cystic lesion that is not lined by true epithelium. The third mechanism may involve the blockage of the mucous gland, which does not rupture in due course of time. The gland continues producing mucus and if the gland is in the connective tissue stroma of the sinus lining, as it expands it, too, might reflect the normal sinus lining. This process leads to a cavity formation which is filled with mucus and lined with epithelium. Lastly, the fourth mechanism may be blockage of the sinus ostium and pooling of the mucous discharge from the mucous glands leading to the formation of a cystic cavity. In such a scenario, the cyst will be lined entirely by the original sinus membrane containing mucus, but it's doubtful that the contents will be sterile, however, as is generally the case in mucoceles. In our present case, the second or third mechanism may be the reason behind the development of mucocele, as in other two mechanism the cystic content may be purulent. $(9,10)$

In case of bone destruction, mucocele should be extricated from other malignant conditions of sinus and tumors of dental origin and for this biopsy must be done to attest the diagnosis. Only based on CT scan noninfected maxillary mucoceles can't be forfended, as it adduces as homogenous lesions, which are isodense with the brain. $(11,12)$

The treatment of maxillary sinus mucoceles is surgery. Traditionally it is done via the Caldwell-Luc technique with total removal of the sinusal mucous membrane followed by inferior antrostomy, which ensures ventilation and drainage of the sinus. Lately, endoscopic marsupialization is more weighed as it has less morbidity with a very low recurrence rate. (13)

\section{3 | CONCLUSION}

Confined maxillary sinus mucocele is a rare pathology. It is arduous to characterize it from other types of cysts or neoplasms of sinus preoperatively and when bone destruction and expansion occur, it can be confounded with malignant diseases. To preclude pathology specific investigation must be encouraged as it will facilitate successful treatment outcome. If mucocele presents early then it is possible to obviate the need for superfluous invasive procedures and protracted treatment time.

FINANCIAL SUPPORT AND SPONSORSHIP Nil.

\section{4 | CONFLICTS OF INTEREST}

There are no conflicts of interest.

\section{REFERENCES}

1. Zizmor J, Noyek AM, Chapnik JS. Mucocele of the paranasal sinuses. Can J Otolaryngol (Supp I). $1974 ; 3$. 
2. Ozcan M, Akdoğan Ö, Gün T. Giant Mucocele of the Maxillary Antrum: Report of a Case. Turk Arch Otolaryngol. 2002;40(2):150-152.

3. Agha RA, Borrelli MR, Farwana R, Koshy K, Fowler AJ, Orgill DP. The SCARE 2018 statement: updating consensus Surgical CAse REport (SCARE) guidelines. Int J Surg Lond Engl. 2018;60:132-136.

4. Natvig K, Larsen TE. Mucocele of the paranasal sinuses. J Laryngol Otol. 1978;92(12):10751082.

5. Black's medical dictionary;p. 471-471.

6. Gleeson MJ, Clarke RC, Otorhinolaryngology SB. CRC Press; 2008.

7. Jones NS. Management of the frontal sinus. In: VJ L, editor. Cummings Otolaryngology- Head and Neck Surgery. Mosby Elsevier; 2010. p. 783-783.

8. Jayaraj SM, Patel SK, Ghufoor K, Frosh AC. Mucoceles of the maxillary sinus. Int J Clin Pract. 1999;53(5):391-394.

9. Marks SC, Latoni JD, Mathog RH. Mucoceles of the maxillary sinus. Otolaryngol Head Neck Surg. 1997;117:18-21.
10. Menezes J, Moura L, Pereira-Filho V, HochuliVieira E. Maxillary sinus mucocele as a late complication in zygomatic-orbital complex fracture. Craniomaxillofacial Trauma Reconstr. 2016;09(04):342-344.

11. Martel-Martin M, Gras-Cabrerizo JR, BotheGonzalez C, Montserrat-Gili JR, Juan-Delago $\mathrm{D}$, Massegur-Solench M, et al. Clinical analysis and surgical results of 58 paranasal sinus mucoceles. Acta Otorrinolaringol Esp. 2015;66:9299.

12. Maxillary sinus mucocele Report of an unusual case Robert E Barsley, Kavas H Thunthy, and Jim C Weir Oral Slug. 1984;58.

13. Caylakli F, Yavuz H, Cagici AC, Ozluoglu LN. Endoscopic sinus surgery for maxillary sinus mucoceles. Head Face Med. 2006;2:29-29.

How to cite this article: D.M.S., D.S.C., D.G.V. Giant Mucocele of Maxillary Sinus, Scarce Occurrence: Case Report. Journal of Medical Research and Health Sciences. 2022;1774-1778. ht tps://doi.org/10.52845/JMRHS/2022-5-2-2 